\title{
Spatial epidemiology of dry eye disease: findings from South Korea
}

\author{
Sun-Bi Um ${ }^{1}$, Na Hyun Kim ${ }^{1}$, Hyung Keun Lee ${ }^{2}$, Jong Suk Song ${ }^{3}$ and Hyeon Chang Kim ${ }^{4}$
}

\begin{abstract}
Background: DED rate maps from diverse regions may allow us to understand world-wide spreading pattern of the disease. Only few studies compared the prevalence of DED between geographical regions in non-spatial context. Therefore, we examined the spatial epidemiological pattern of DED prevalence in South Korea using a nationally representative sample.

Methods: We analyzed 16,431 Korean adults aged 30 years or older of the 5th Korea National Health and Nutrition Examination Survey. DED was defined as previously diagnosed by an ophthalmologist as well as symptoms experienced. Multiple logistic regression analysis was used to assess the spatial pattern in the prevalence of DED, and effects of environmental factors.
\end{abstract}

Results: Among seven metropolitan cities and nine provinces, three metropolitan cities located in the southeast of Korea revealed the highest prevalence of DED. After adjusting for sex, age and survey year, people living in urban areas had higher risk of having DED. Adjusted odds ratio for having previously diagnosed DED was 1.677 (95\% Cl 1.299-2.166) for metropolitan cities and 1.580 (95\% Cl 1.215-2.055) for other cities compared to rural areas. Corresponding odds ratio for presenting DED symptoms was 1.388 (95\% Cl 1.090-1.766) for metropolitan cities and 1.271 (95\% Cl 0.999-1.617) for other cities. Lower humidity and longer sunshine duration were significantly associated with DED. Among air pollutants, $\mathrm{SO}_{2}$ was associated with DED, while $\mathrm{NO}_{2}, \mathrm{O}_{3}, \mathrm{CO}$, and PM10 were not.

Conclusion: Our findings suggest that prevalence of DED can be affected by the degree of urbanization and environmental factors such as humidity and sunshine duration.

Keywords: Air pollutants, Dry eye disease, Meteorological factors, Prevalence, Spatial epidemiology

\section{Background}

Dry eye disease (DED) causes great discomfort on individual lives and is a rising public health issue. Previous studies revealed common symptoms of DED such as visual disturbance, ocular fatigue and pain are affecting the performance of daily activities and quality of life [1-7]. The prevalence of DED is continuously growing worldwide with a prevalence ranging from $4.3 \%$ to $73.5 \%$ [2-4,8-17], and it is one of the major reasons to seek eye care $[6,7,18]$. Studies indicated that old age and female sex are established risk factors of DED $[3,10,14]$. The prevalence of DED was comparably higher in Asian population than in Western population $[9,11,12,17]$. Yet, lack of effort in identifying the relationship between

\footnotetext{
* Correspondence: hckim@yuhs.ac

${ }^{4}$ Department of Preventive Medicine, Yonsei University College of Medicine, 50-1Yonsei-ro, Seodaemun-gu, Seoul 120-752, Republic of Korea

Full list of author information is available at the end of the article
}

DED and region is largely unexplored. Within USA, prevalence of DED was the highest in south, but explanation on why south had the highest prevalence was not mentioned [12]. Another study performed in South Korea identified that DED prevalence was higher in urban areas than in rural areas [19]. However, this study was limited to the population of a single city, and regional characteristics were not investigated as main factors in relation to DED.

Examining geographical pattern in disease prevalence is important in epidemiology by providing health professionals with visual evidence for generating effective community-based strategies [20-22]. However, despite growing interest in this issue, only few studies empirically explored the spatial epidemiology of the prevalence of DED. Spatial epidemiology emerges as a key tool to
Ciomed Central (c) 2014 Um et al.; licensee BioMed Central Ltd. This is an Open Access article distributed under the terms of the Creative Commons Attribution License (http://creativecommons.org/licenses/by/4.0), which permits unrestricted use, distribution, and reproduction in any medium, provided the original work is properly credited. The Creative Commons Public Domain Dedication waiver (http://creativecommons.org/publicdomain/zero/1.0/) applies to the data made available in this article, unless otherwise stated. 
identify the spread and possible causes of DED outbreaks since standard map display techniques enable the visualization of DED uncertainty and ensure more meaningful inferences from the spatial data. Inter-community DED figures compare the number of expected cases in the standard population with the number observed. It is expected that such direct standardization allows valid comparison of DED risks from exposure group in different countries.

Therefore, we investigated the spatial epidemiological pattern of DED prevalence in South Korea using the data from the 5th Korea National Health and Nutrition Examination Survey (KNHANES), and further assessed the effect of regional characteristics such as city size, meteorological factors and air pollutants. Although South Korea has been elected as a case study, this study may be relevant for other countries having similar spatial epidemiology contexts in relation to DED.

\section{Results}

Prevalence of DED by sex, age, and region

Table 1 presents the prevalence of DED by sex, age, and region. Presence of DED was defined in two ways; having previously diagnosed DED and having DED symptoms. In this nationally representative sample, $10.4 \%$ (1,616 over $15,538)$ reported that they have been diagnosed as DED, and $17.7 \%(2,666$ over 15,034$)$ reported that they had symptoms of DED. A total of 1,314 people reported both previously diagnosed DED and DED symptoms. Both previously diagnosed DED and DED symptoms were more frequent in women $(12.7 \%$ and $19.4 \%$, respectively) than in men (4.6\% and $9.8 \%$, respectively). Prevalence of DED diagnosis and symptoms were higher in participants aged 60 to 69 (11.5\% and 17.5\%, respectively). Prevalence of DED diagnosis was highest in Ulsan (13.5\%), followed by Busan (12.5\%) and Daegu (10.6\%). Similarly, DED symptoms were most frequent among participants residing in

Table 1 Prevalence of dry eye disease by participant's characteristics

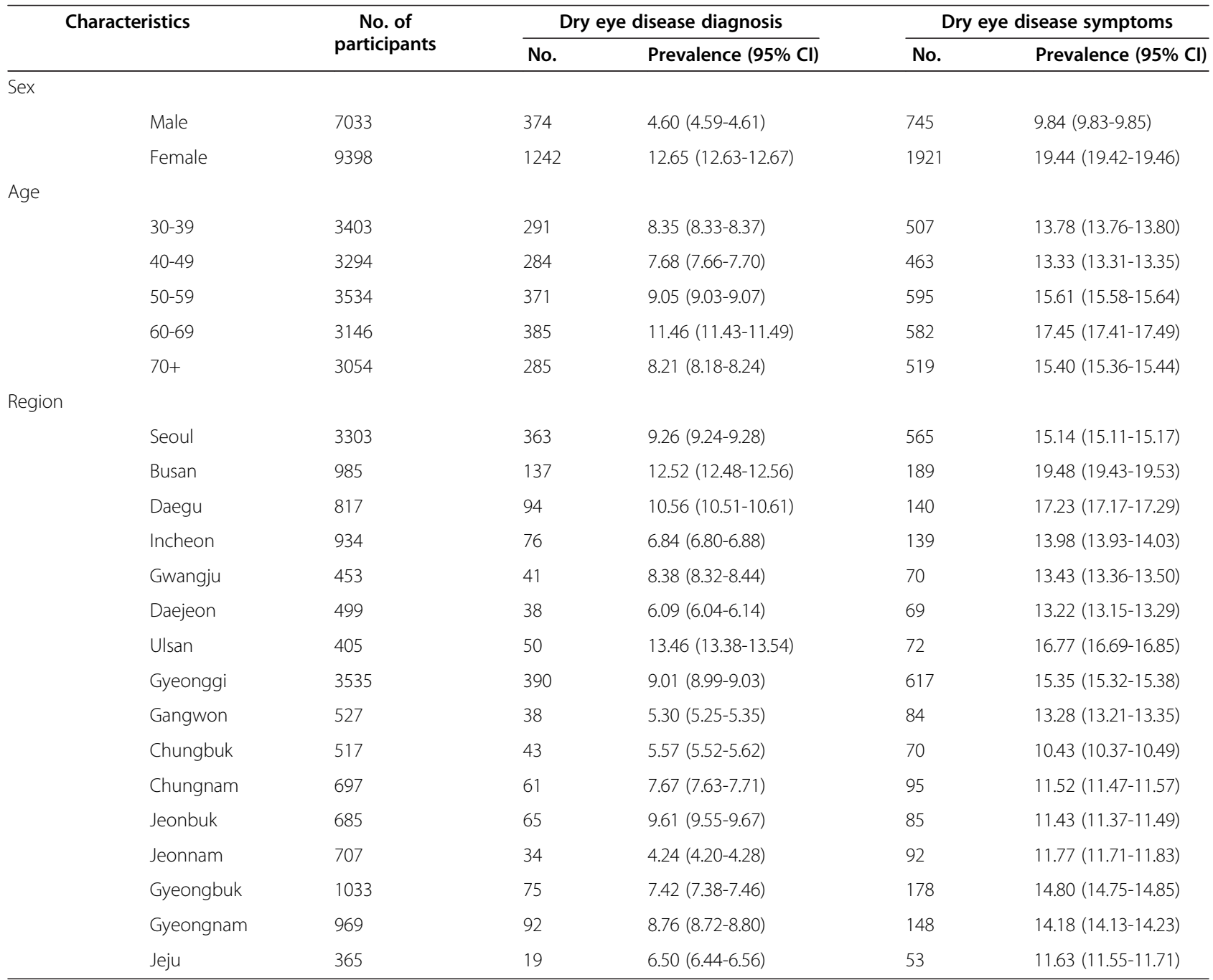

Prevalence and confidence intervals were estimated with considering sampling weights. 
Busan (19.5\%), Ulsan (16.8\%), and Daegu (17.2\%), though in a different order. Referring to Figure 1, which visually displays the prevalence of DED diagnosis and symptoms by region in South Korea, Ulsan, Busan, and Daegu metropolitan cities are located in the south east side of the peninsula.

Table 2 presents the results of serial logistic regression analyses. Compared to men, women had a higher odds ratio for previously diagnosed DED and symptoms of DED. People with age 60 to 69 had the highest odds ratio for DED diagnosis and DED symptoms. Prevalence of DED diagnosis showed statistically significant regional difference by revealing the highest odds in Ulsan (OR 1.74; 95\% CI 1.19-2.54) and Busan (OR 1.47; 95\% CI 1.04-2.06), and the lowest odds in Daejeon (OR 0.66; 95\% CI 0.43-0.99), Gangwon (OR 0.55; 95\% CI 0.360.84 ), and Jeonnam (OR 0.43; 95\% CI 0.23-0.81). These associations remained significant after adjustment for sex, age, region, and survey year. Frequency of DED symptoms showed similar regional difference, though after adjustments the significance disappeared.

\section{Relationship between DED and regional characteristics}

Table 3 presents the relationship between regional characteristics and the prevalence of DED. In the unadjusted analysis, both diagnosis and symptoms of DED revealed significantly higher odds in metropolitan cities compared to rural areas with an OR of 1.654 (95\% CI 1.297-2.110) and 1.352 (95\% CI 1.075-1.700), respectively. After adjustment, the associations were still consistently significant. Non-metropolitan cities also revealed higher odds for DED than rural areas. However, the difference between non-metropolitan cities and rural area was statistically significant for DED diagnosis, but not for symptoms of DED. Moving on to meteorological factors, prevalence of previous DED diagnosis was positively associated with higher temperature (OR 1.076; 95\% CI 1.009-1.148) and longer sunshine duration (OR 1.015 ; $95 \%$ CI $1.006-1.023)$, and negatively associated with higher humidity (OR 0.970; 95\% CI $0.955-0.986$ ) after adjusting for sex, age, and survey year. Presenting DED symptoms was positively associated with longer sunshine duration (OR 1.013; 95\% CI 1.005-1.021) and negatively associated with higher humidity (OR 0.975; 95\% CI 0.959-0.991) when adjusted for sex, age, and survey year. Among the five air pollutants analyzed, only $\mathrm{SO}_{2}$ concentration had a significantly positive association with DED diagnosis (OR 1.092; 95\% CI 1.011-1.179) and DED symptoms (OR 1.092; 95\% CI 1.005-1.187) after adjusting for sex, age, and survey year.

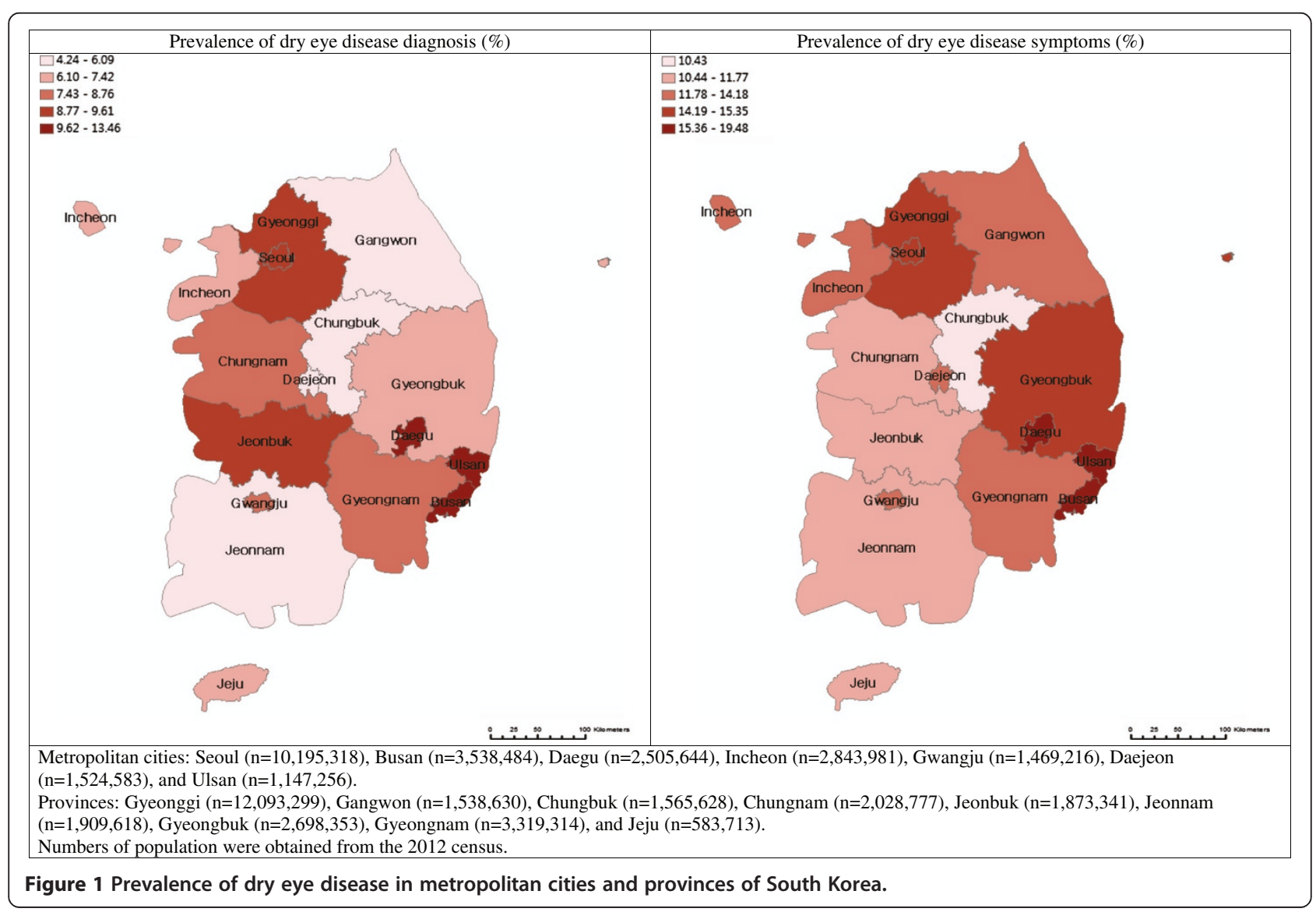


Table 2 Association between dry eye disease and participant's characteristics

\begin{tabular}{|c|c|c|c|c|c|c|}
\hline \multirow[t]{2}{*}{ Characteristics } & \multicolumn{3}{|c|}{$\begin{array}{l}\text { Odds ratio (95\% confidence interval) for dry eye } \\
\text { disease diagnosis }\end{array}$} & \multicolumn{3}{|c|}{$\begin{array}{l}\text { Odds ratio (95\% confidence interval) for dry eye } \\
\text { disease symptoms }\end{array}$} \\
\hline & Unadjusted & $\begin{array}{l}\text { Adjusted for } \\
\text { sex and age }\end{array}$ & $\begin{array}{l}\text { Adjusted for sex, } \\
\text { age, region, and } \\
\text { survey year }\end{array}$ & Unadjusted & $\begin{array}{l}\text { Adjusted for } \\
\text { sex and age }\end{array}$ & $\begin{array}{l}\text { Adjusted for sex, } \\
\text { age, region, and } \\
\text { survey year }\end{array}$ \\
\hline \multicolumn{7}{|l|}{ Sex } \\
\hline Male & 1.00 & 1.00 & 1.00 & 1.00 & 1.00 & 1.00 \\
\hline Female & $2.98(2.58-3.45)$ & $3.00(2.59-3.46)$ & $3.02(2.61-3.50)$ & $2.20(1.95-2.47)$ & $2.19(1.95-2.46)$ & $2.21(1.96-2.48)$ \\
\hline \multicolumn{7}{|l|}{ Age } \\
\hline $30-39$ & 1.00 & 1.00 & 1.00 & 1.00 & 1.00 & 1.00 \\
\hline $40-49$ & $0.91(0.74-1.13)$ & $0.91(0.73-1.13)$ & $0.91(0.73-1.13)$ & $0.97(0.81-1.16)$ & $0.97(0.80-1.16)$ & $0.97(0.80-1.16)$ \\
\hline $50-59$ & $1.07(0.86-1.33)$ & $1.06(0.85-1.32)$ & $1.06(0.85-1.31)$ & $1.12(0.94-1.34)$ & $1.12(0.93-1.33)$ & $1.11(0.93-1.33)$ \\
\hline $60-69$ & $1.39(1.13-1.71)$ & $1.34(1.09-1.66)$ & $1.37(1.11-1.68)$ & $1.28(1.08-1.53)$ & $1.25(1.05-1.49)$ & $1.26(1.06-1.51)$ \\
\hline $70+$ & $0.97(0.77-1.22)$ & $0.86(0.68-1.08)$ & $0.90(0.71-1.14)$ & $1.12(0.93-1.35)$ & $1.02(0.84-1.23)$ & $1.06(0.87-1.29)$ \\
\hline \multicolumn{7}{|l|}{ Region } \\
\hline Seoul & $1.01(0.81-1.26)$ & $0.99(0.79-1.23)$ & $0.99(0.79-1.24)$ & $0.97(0.78-1.22)$ & $0.96(0.76-1.20)$ & $0.96(0.76-1.20)$ \\
\hline Busan & $1.47(1.04-2.06)$ & $1.42(1.00-2.02)$ & $1.43(1.01-2.03)$ & $1.41(1.02-1.96)$ & $1.38(0.98-1.94)$ & 1.37 (0.97-1.93) \\
\hline Daegu & $1.19(0.87-1.64)$ & $1.15(0.84-1.58)$ & $1.16(0.85-1.58)$ & $1.35(0.98-1.85)$ & $1.29(0.93-1.80)$ & $1.28(0.92-1.77)$ \\
\hline Incheon & $0.72(0.51-1.02)$ & $0.71(0.50-1.03)$ & $0.72(0.50-1.03)$ & $0.88(0.58-1.33)$ & $0.87(0.57-1.33)$ & $0.87(0.57-1.33)$ \\
\hline Gwangju & $0.87(0.49-1.56)$ & $0.88(0.48-1.61)$ & $0.88(0.51-1.51)$ & $0.83(0.47-1.47)$ & $0.84(0.47-1.47)$ & $0.83(0.49-1.41)$ \\
\hline Daejeon & $0.66(0.43-0.99)$ & $0.64(0.43-0.96)$ & $0.61(0.38-0.98)$ & $0.82(0.55-1.22)$ & $0.81(0.55-1.20)$ & $0.78(0.49-1.23)$ \\
\hline Ulsan & $1.74(1.19-2.54)$ & $1.74(1.17-2.59)$ & $1.84(1.25-2.71)$ & $1.38(0.79-2.41)$ & $1.35(0.77-2.36)$ & $1.41(0.86-2.33)$ \\
\hline Gyeonggi & 1.00 & 1.00 & 1.00 & 1.00 & 1.00 & 1.00 \\
\hline Gangwon & $0.55(0.36-0.84)$ & $0.54(0.35-0.83)$ & $0.53(0.34-0.84)$ & $0.87(0.55-1.35)$ & $0.85(0.54-1.33)$ & $0.84(0.55-1.29)$ \\
\hline Chungbuk & $0.58(0.30-1.10)$ & $0.59(0.32-1.11)$ & $0.62(0.33-1.18)$ & $0.61(0.26-1.43)$ & $0.62(0.27-1.43)$ & $0.65(0.29-1.44)$ \\
\hline Chungnam & $0.81(0.48-1.36)$ & $0.78(0.46-1.30)$ & $0.78(0.47-1.30)$ & $0.72(0.43-1.20)$ & $0.68(0.41-1.14)$ & $0.68(0.41-1.13)$ \\
\hline Jeonbuk & $1.04(0.69-1.58)$ & $1.01(0.66-1.54)$ & $1.01(0.67-1.52)$ & $0.70(0.47-1.07)$ & $0.68(0.45-1.04)$ & $0.68(0.45-1.03)$ \\
\hline Jeonnam & $0.43(0.23-0.81)$ & $0.39(0.21-0.74)$ & $0.39(0.20-0.74)$ & $0.73(0.45-1.20)$ & $0.67(0.40-1.11)$ & $0.65(0.39-1.09)$ \\
\hline Gyeongbuk & $0.81(0.50-1.30)$ & $0.77(0.47-1.26)$ & $0.78(0.48-1.27)$ & $0.97(0.67-1.40)$ & $0.93(0.64-1.36)$ & $0.94(0.64-1.37)$ \\
\hline Gyeongnam & $0.94(0.66-1.34)$ & $0.93(0.65-1.32)$ & $0.92(0.65-1.31)$ & $0.92(0.66-1.27)$ & $0.90(0.65-1.24)$ & $0.89(0.65-1.22)$ \\
\hline Jeju & $0.68(0.46-1.00)$ & $0.67(0.45-1.00)$ & $0.71(0.45-1.10)$ & $0.83(0.51-1.35)$ & $0.79(0.46-1.36)$ & $0.83(0.46-1.52)$ \\
\hline
\end{tabular}

Odds ratio and confidence intervals were estimated with considering sampling weights.

Post-hoc subgroup analyses were performed by survey year and participant's sex. Urban areas revealed a higher prevalence of DED compared to rural areas regardless of survey year, though the overall prevalence increased between 2010 and 2012 (Additional file 1: Tables S1 and S2). Similar regional patterns of DED prevalence were observed for men and women (Additional file 1: Tables S3 and S4).

\section{Discussion}

South Korea is located in East Asia with large numbers of mountains and rivers crisscrossing the peninsula. The country is divided into notable urban and rural areas with four distinct seasons. The population is a relatively homogeneous society with an absolute majority of Korean ethnicity [19]. Even though South Korea's land area is small, due to its unique characteristics this nation is a suitable site to compare the prevalence of DED between urban and rural areas [19]. We did not investigate the effects of ethnicity on DED, but the ethnicity might not contribute to the prevalence of DED in the present study as reported in the West.

Similar to previous studies $[2,3,8,12,14]$, our findings also reported that middle aged or older women has an increased risk of suffering from DED. Our study also observed that people in their age 60s reported highest frequency of previous DED diagnosis as well as symptoms of DED. Moving on to region, our results pointed out that the prevalence of DED is higher in most metropolitan cities. Ulsan metropolitan city marked the highest prevalence and the highest odds for previously diagnosed DED before and after sex, age, region, and survey year 
Table 3 Association between dry eye disease and regional characteristics

\begin{tabular}{|c|c|c|c|c|c|c|}
\hline \multirow[t]{2}{*}{$\begin{array}{l}\text { Regional } \\
\text { characteristics }\end{array}$} & \multicolumn{3}{|c|}{$\begin{array}{c}\text { Odds ratio (95\% confidence interval) for dry eye } \\
\text { disease diagnosis }\end{array}$} & \multicolumn{3}{|c|}{$\begin{array}{c}\text { Odds ratio (95\% confidence interval) for dry eye } \\
\text { disease symptoms }\end{array}$} \\
\hline & Unadjusted & $\begin{array}{l}\text { Adjusted for } \\
\text { sex and age }\end{array}$ & $\begin{array}{l}\text { Adjusted for sex, } \\
\text { age, and survey year }\end{array}$ & Unadjusted & $\begin{array}{l}\text { Adjusted for } \\
\text { sex and age }\end{array}$ & $\begin{array}{l}\text { Adjusted for sex, } \\
\text { age, and survey year }\end{array}$ \\
\hline \multicolumn{7}{|l|}{ City Size } \\
\hline $\begin{array}{l}\text { Metropolitan } \\
\text { Cities }\end{array}$ & $1.654(1.297-2.110)$ & $1.689(1.314-2.171)$ & $1.677(1.299-2.166)$ & $1.352(1.075-1.700)$ & $1.390(1.096-1.765)$ & $1.388(1.090-1.766)$ \\
\hline Other Cities & $1.554(1.206-2.002)$ & $1.594(1.229-2.067)$ & $1.580(1.215-2.055)$ & $1.229(0.970-1.558)$ & $1.272(0.996-1.624)$ & $1.271(0.999-1.617)$ \\
\hline Rural & 1.00 & 1.00 & 1.00 & 1.00 & 1.00 & 1.00 \\
\hline \multicolumn{7}{|l|}{$\begin{array}{l}\text { Meteorological factor } \\
\text { (1-SD increase) }\end{array}$} \\
\hline $\begin{array}{l}\text { Average } \\
\text { Temperature }\end{array}$ & $1.073(1.009-1.141)$ & $1.069(1.004-1.138)$ & $1.076(1.009-1.148)$ & $1.073(1.007-1.145)$ & $1.067(0.998-1.140)$ & $1.065(0.996-1.138)$ \\
\hline $\begin{array}{l}\text { Average Wind } \\
\text { Speed }\end{array}$ & $1.028(0.912-1.158)$ & $1.019(0.902-1.151)$ & $1.009(0.892-1.140)$ & $1.075(0.952-1.214)$ & $1.064(0.939-1.205)$ & $1.054(0.928-1.198)$ \\
\hline Average Humidity & 0.964 (0.949-0.979) & $0.964(0.949-0.979)$ & $0.970(0.955-0.986)$ & $0.971(0.956-0.987)$ & $0.971(0.956-0.987)$ & $0.975(0.959-0.991)$ \\
\hline Sunshine Duration & $1.016(1.010-1.021)$ & $1.016(1.010-1.022)$ & $1.015(1.006-1.023)$ & $1.012(1.008-1.017)$ & $1.013(1.008-1.018)$ & $1.013(1.005-1.021)$ \\
\hline Precipitation & $1.000(0.997-1.003)$ & $1.000(0.997-1.003)$ & $1.002(0.999-1.006)$ & $0.998(0.995-1.000)$ & $0.998(0.995-1.000)$ & $1.000(0.997-1.003)$ \\
\hline \multicolumn{7}{|l|}{$\begin{array}{l}\text { Air pollutant } \\
\text { (1-SD increase) }\end{array}$} \\
\hline Sulfur dioxide & $1.083(1.007-1.165)$ & $1.082(1.003-1.168)$ & $1.092(1.011-1.179)$ & $1.087(1.001-1.181)$ & $1.087(1.000-1.182)$ & $1.092(1.005-1.187)$ \\
\hline Nitrogen dioxide & $1.006(0.994-1.018)$ & $1.007(0.994-1.019)$ & $1.011(0.998-1.024)$ & $1.003(0.991-1.015)$ & $1.005(0.993-1.017)$ & $1.009(0.996-1.022)$ \\
\hline Ozone & $1.010(0.989-1.031)$ & $1.009(0.987-1.031)$ & $0.991(0.968-1.014)$ & $1.011(0.992-1.031)$ & $1.009(0.988-1.030)$ & $0.995(0.971-1.019)$ \\
\hline Carbon monoxide & $0.999(0.998-1.000)$ & $0.999(0.998-1.000)$ & $0.999(0.998-1.000)$ & $0.999(0.998-1.001)$ & $1.000(0.998-1.001)$ & $1.000(0.999-1.001)$ \\
\hline PM10 & $0.987(0.974-1.000)$ & $0.988(0.974-1.001)$ & $1.014(0.998-1.031)$ & $0.987(0.974-1.000)$ & $0.988(0.974-1.001)$ & $1.010(0.992-1.027)$ \\
\hline
\end{tabular}

Odds ratio and confidence intervals were estimated with considering sampling weights.

adjustment. Ulsan is the most industrialized city and takes the role of maintaining and advancing the Korean economy. According to a study evaluating air pollution and mortality in Seoul and Ulsan metropolitan cities, industrial sources were the major contributing factor of air pollution in Ulsan [23]. This reason might have contributed at least partially to the high prevalence of DED in Ulsan. Busan metropolitan city marked the second highest prevalence and significantly higher odds for DED diagnosis. Busan has the second biggest population and the largest container handling port in South Korea. Daegu showed the third highest prevalence of DED among all regions. Daegu is the fourth largest city in South Korea and has a valley form of terrain, because it is surrounded by low mountains. Since it is trapped by mountains, among 16 administrative districts, Daegu shows the highest temperature in summer in South Korea.

Similar to our results, a few studies observed regional difference of DED, nevertheless none of the studies used spatial epidemiological pattern as a major independent variable $[3,19,24]$. According to a study in Taiwan, majority of patients with DED were residing in urbanized areas [24]. Another study in mainland China also showed that DED symptoms were significantly associated with urban regions [3]. Two studies in Korea showed comparably similar results as our results, though in a non-spatial context. One study compared the prevalence of DED between urban and rural areas within Yongin city, which is located in the Gyeonggi province of South Korea. As a result, residents with DED were mostly residing in urban areas within Yongin city [19]. However, Yongin city is too small to represent the characteristics of urban and rural residents of Korea. Another study analyzed the data collected from KNHANES 2010-2012 and observed that the prevalence of DED among women was low in rural areas [25]. A study in Koumi town, Japan, a rural mountain area, reported the prevalence of clinically diagnosed DED and severe symptoms of DED in men as $2.1 \%$ and $11.5 \%$, respectively, and $7.9 \%$ and $18.7 \%$ in women. After combining the percentages for both clinically diagnosed and severe symptoms of DED, $12.5 \%$ and $21.6 \%$ of men and women were suffering from DED, respectively [26]. The combined prevalence were higher than the prevalence reported from the West [12], but still lower than studies from the East $[2,9]$ which mainly targeted urban areas, and exclusively, the prevalence for clinically diagnosed DED was significantly low compared to the East and West urban regions. Unlike these findings, a study held in Rajasthan, India reported that the prevalence of DED was higher in rural residents (19.6\%) compared to urban 
dwellers (17.5\%) [27], but the association was not statistically significant. This cross-sectional study [27] randomly selected 500 hospital-based patients who presented various ophthalmic problems to a tertiary eye care center and were screened for DED. Rajasthan has a population of 70 million people, and its land area is three times larger than the entire land of South Korea. The hospital-based sample of 500 patients might not represent the DED patients in the total population of Rajasthan. The authors suggested that overwhelming exposure to sunlight, high temperature, and excessive wind contributes to the higher prevalence of DED among rural residents [27].

Spatial pattern of DED might be, at least partially, due to difference of environmental and lifestyle factors between urban and rural areas, though lifestyle factors have not been analyzed in this paper. Regarding meteorological conditions, previous studies suggested humidity, wind speed, and sunshine duration as potential risk factors of DED [27-32]. Our results showed that lower humidity and longer sunshine duration were associated with DED before and after adjusting for covariates. A previous study developed a controlled-environment chamber (CEC) to verify the effects of a low humidity setting on ocular surface in normal mice and found that CEC-kept mice had decreased tear secretion and increased corneal fluorescein staining compared to control mice [30]. Human studies also observed that tear evaporative rate, tear volume, epidermal growth factor, and blink rate were associated with humid condition [28,29,31,32]. Relatively low humidity may increase tear evaporative rate not only in DED patients but also in healthy subjects [28,29,31,32]. Air pollution can be another potential risk factor of DED $[27,33]$. In our study, $\mathrm{SO}_{2}$ concentration was the only factor associated with DED after adjusted for sex, age and survey year. Concentration of $\mathrm{CO}$ was associated with DED when unadjusted or sex- and age- adjusted. Though further investigation is required for the association between DED and air pollutants, our results indicate that chronic exposure to disturbing environment can be a potential risk factor of DED.

Our study has several limitations to be discussed. First, this study used questionnaire-based assessment to estimate prevalence of DED. Nevertheless, questionnaire interview on DED diagnosis and symptoms were done by trained ophthalmologists. Evaluation of eye disease in the KNHANES was performed and monitored by the Korean Ophthalmological Society. According to a survey by the Korean Corneal Disease Study Group, 79\% of corneal subspecialists use the Dry Eye Workshop classification [18] and 21\% use the Dysfunctional Tear Syndrome Study Group guidelines [34] to diagnose DED [35]. This states that most ophthalmologists follows a certain guideline when diagnosing DED, however not knowing which diagnostic criteria used is one of the limitations for this study. The KNHANES questionnaire for DED symptoms included only dryness and irritation, therefore lack of information on detecting DED symptoms may lead to misclassification. However, studies reported significant associations between clinical signs and symptoms of DED [36-38]. Subjective method of DED diagnosis also has a clinical value, since DED symptoms directly affect the quality of life $[35,39]$. Second, the KNHANES was designed to estimate disease prevalence for the entire Korean population and for each metropolitan city or province. Thus, we were unable to investigate the effects caused by regional characteristics at smaller area units. Third, we did not controlled socioeconomic factors, medical history, and other variables that might be linked with DED. Lastly, the analysis involved residents of only in Korea, and therefore the results may not be generalizable to other populations. Despite these limitations, this is the first study that compared the prevalence of DED in different regions of South Korea, by using visual aid and statistical analysis along with environmental factors. This study used a large nationally representative dataset with a stratified analysis with sufficient statistical power.

\section{Conclusions}

In conclusion, the prevalence of DED differs by region revealing a high prevalence and significant association in most metropolitan cities. Meteorological factors such as annual average humidity and sunshine duration were associated with DED. Further investigation is required to determine whether specific air pollutants play a role in the development of DED. Additionally, more studies are needed to establish the causal effects of environmental drivers such as urbanization, meteorological factors, air pollutants, and population density on the development of DED.

This paper contributes to the literature by presenting comparable spatial epidemiological pattern of the prevalence of DED. The large nationwide sample allowed us to examine whether the prevalence of DED varied according to the urban, rural, and industrial areas. Although further research is required, the results confirm the regional difference of DED prevalence and provide a basis for comparison with other countries and a methodological framework for examining spatial epidemiological pattern of DED in the context of worldwide regional communities.

\section{Methods}

\section{Study subjects}

Data for this study were derived from the 5th Korea National Health and Nutrition Examination Survey (KNHANES) which was conducted from 2010 to 2012 by the Korea Centers for Disease Control and Prevention (KCDC). Between 1998 and 2005, the KNHANES has 
been performed every three years as a short-term research operating system, but the survey has been conducted annually since 2007. Survey data from 2007 to 2009 were collected and named as the 4th KNHANES and survey data for the 5th KNHANES were collected during 2010 through 2012. Among 16,431 participants aged 30 years or older, 893 people were non-responsive for previous DED diagnosis, and 1,397 were non-responsive for DED symptoms. Thus, 15,538 and 15,034 participants were analyzed for previous DED diagnosis and DED symptoms, respectively. Each year, the survey protocol and informed consent forms are approved by the Institutional Review Board of the KCDC. The KNHANES complied with the tenets of the Declaration of Helsinki. The KNHANES is an ongoing nationally representative study, and deidentified datasets are publicly available from the KCDC. More detailed description of the KNHANES can be found elsewhere [40,41].

Regarding sampling units, the KNHANES uses a stratified multistage probability sampling design based on geographic area, sex, and age group to obtain information that represents non-institutionalized civilian population of South Korea. The survey consists of three parts: health interview survey, health examination survey, and nutrition survey. Survey questionnaires were asked by a trained staff, and the examination components were administered by highly trained medical personnel. Demographic information of each participant was collected from a prepared questionnaire. Ophthalmologic examinations were included first in 2008, and questionnaires on DED were introduced since 2010. South Korea is divided into 16 administrative divisions including nine provinces (Gyeonggi, Gangwon, Chungbuk, Chungnam, Jeonbuk, Jeonnam, Gyeongbuk, Gyeongnam, and Jeju), six metropolitan cities (Busan, Daegu, Incheon, Gwangju, Daejeon, and Ulsan), and one capital metropolitan city (Seoul). Korea's administrative regions can be classified into three groups based on the population size: counties (less than 50,000), cities (more than 50,000), and metropolitan cities (more than 1,000,000). The six provinces are composed of over 200 counties and cities. Non-metropolitan cities within a province have a characteristic of an urbanized city, and counties resemble the nature of a typical rural region. To analyze the representative national data of the prevalence of DED in South Korea, three years' datasets (2010, 2011 and 2012) were combined.

\section{Dry eye disease}

Ophthalmologists designated by the Korean Ophthalmological Society performed eye examinations. The KCDC and the Korean Ophthalmological Society conducted education and training program twice a year. Educational information included the overall purpose of eye disease epidemiological studies, cautions, machine operation, and diagnosis and classification of major eye disorders. Eye disease questionnaires included frequency of eye screening, hours of sun exposure, family history of eye disease, past history of eye disease including DED, glaucoma, cataracts, and age-related macular degeneration.

\section{Environmental factors}

Meteorological factors for each administrative district since 2010 to 2012 were obtained from the National Climate Data Service System. Average temperature and humidity were measured 8 times 3 hours apart for every single day. Average wind speed was divided by the total value of artistic air for the entire day over 86,400 seconds. Sunshine duration was defined as hours of sun rays without blockage of clouds or fogs. Precipitation was measured by the total amount of precipitation for 24 hours, daily. Data for regional air pollutants were acquired from the Ministry of Environment. $\mathrm{SO}_{2}, \mathrm{NO}_{2}, \mathrm{O}_{3}, \mathrm{CO}$, and PM10 were measured and analyzed at 250 national metrological locations in South Korea. For our analysis annual average values were encountered.

\section{Statistical analysis}

Weighted analyses were performed for prevalence and odds ratio of DED, since KNHANES provides weights to compensate with its complex sampling design [25]. Serial multiple logistic regression models were used to calculate the odds ratio (OR) and 95\% confidence interval (95\% CI) for previously diagnosed DED and symptoms. Gyeonggi province was selected as a reference for analyzing the association between DED and region, because Gyeonggi had the highest number of people who participated in the survey. The above analyzing method was used once again to determine the association between DED and environmental factors (test of odds ratio for a 1-SD increase). Statistical analyses were performed using SAS Version 9.2 (SAS Institute, Inc. Cary, NC). To visually display the prevalence of DED by region, ArcGIS Version 10.1 (Esri Headquarters, Redlands, CA) was used.

\section{Additional file}

Additional file 1: Table S1. Change in previous dry eye disease diagnosis between 2010 and 2012 by region. Table S2. Change in dry eye disease symptoms experienced between 2010 and 2012 by region. Table S3. Prevalence of and odds ratio for dry eye disease in men. Table S4. Prevalence of and odds ratio for dry eye disease in women.

\section{Abbreviations}

Cl: Confidence interval; DED: Dry eye disease; KCDC: Korea center for disease control and prevention; KNHANES: Korea national health and nutrition examination survey; OR: Odds ratio; SD: Standard deviation.

\section{Competing interests}

The authors declare that they have no competing interest. 


\section{Author's contributions}

SBU searched literatures, analyzed data and wrote the manuscript. NHK assisted with the statistical analyses. HKL and JSS critically revised and helped to draft the manuscript. HCK conceptualized the entire manuscript by providing guidance in designing analyses and contributed to writing the manuscript. All authors edited and approved the final manuscript.

\section{Acknowledgements}

Thanks are extended to the different national agencies of South Korea (Korea Centers for Disease Control and Prevention and the National Climate Data Service System) for providing their data for this manuscript. The authors gratefully acknowledge the support by a grant from the Korean Health Technology R\&D Project, Ministry of Health \& Welfare, Republic of Korea (HI3C0055).

\section{Author details}

'Department of Public Health, Yonsei University Graduate School, Seoul, South Korea. ${ }^{2}$ Institute of Vision Research, Department of Ophthalmology, Yonsei University College of Medicine, Seoul, South Korea. ${ }^{3}$ Department of Ophthalmology, Korea University College of Medicine, Seoul, South Korea. ${ }^{4}$ Department of Preventive Medicine, Yonsei University College of Medicine, 50-1Yonsei-ro, Seodaemun-gu, Seoul 120-752, Republic of Korea.

Received: 31 May 2014 Accepted: 11 August 2014

Published: 15 August 2014

\section{References}

1. Moss SE, Klein R, Klein BE: Long-term incidence of dry eye in an older population. Optom Vis Sci 2008, 85(8):668-674

2. Lekhanont K, Rojanaporn D, Chuck RS, Vongthongsri A: Prevalence of dry eye in Bangkok, Thailand. Cornea 2006, 25(10):1162-1167. doi:1110.1097/ 1101.ico.0000244875.0000292879.0000244871a.

3. Jie $Y, X u L, W u$ YY, Jonas JB: Prevalence of dry eye among adult Chinese in the Beijing eye study. Eye (Lond) 2009, 23(3):688-693.

4. DEWS: The epidemiology of dry eye disease: report of the epidemiology subcommittee of the international dry eye workshop (DEWS). Ocul Surf 2007, 5:93-107.

5. Tong L, Waduthantri S, Wong TY, Saw SM, Wang JJ, Rosman M, LamoureuX E: Impact of symptomatic dry eye on vision-related daily activities: the Singapore Malay Eye Study. Eye (Lond) 2010, 24(9):1486-1491.

6. Miljanovic B, Dana R, Sullivan DA, Schaumberg DA: Impact of dry eye syndrome on vision-related quality of life. Am J Ophthalmol 2007 143(3):409-415.

7. Le Q, Zhou X, Ge L, Wu L, Hong J, Xu J: Impact of dry eye syndrome on vision-related quality of life in a non-clinic-based general population. BMC Ophthalmol 2012, 12:22.

8. Moss SE, Klein R, Klein BE: Prevalence of and risk factors for dry eye syndrome. Arch Ophthalmol 2000, 118(9):1264-1268.

9. Lee AJ, Lee J, Saw SM, Gazzard G, Koh D, Widjaja D, Tan DT: Prevalence and risk factors associated with dry eye symptoms: a population based study in Indonesia. Br J Ophthalmol 2002, 86(12):1347-1351.

10. Chia EM, Mitchell P, Rochtchina E, Lee AJ, Maroun R, Wang JJ: Prevalence and associations of dry eye syndrome in an older population: the blue mountains eye study. Clin Experiment Ophthalmol 2003, 31(3):229-232.

11. Lin PY, Tsai SY, Cheng CY, Liu JH, Chou P, Hsu WM: Prevalence of dry eye among an elderly Chinese population in Taiwan: the Shihpai eye study. Ophthalmology 2003, 110(6):1096-1101.

12. Schaumberg DA, Sullivan DA, Buring JE, Dana MR: Prevalence of dry eye syndrome among US women. Am J Ophthalmol 2003, 136(2):318-326.

13. Uchino M, Schaumberg DA, Dogru M, Uchino Y, Fukagawa K, Shimmura S, Satoh T, Takebayashi T, Tsubota K: Prevalence of dry eye disease among Japanese visual display terminal users. Ophthalmology 2008, 115(11):1982-1988.

14. Viso E, Rodriguez-Ares MT, Gude F: Prevalence of and associated factors for dry eye in a Spanish adult population (the Salnes Eye Study). Ophthalmic Epidemiol 2009, 16(1):15-21.

15. Caffery BE, Richter D, Simpson T, Fonn D, Doughty M, Gordon K: CANDEES. The Canadian dry eye epidemiology study. Adv Exp Med Biol 1998, 438:805-806.
16. Uchino M, Dogru M, Yagi Y, Goto E, Tomita M, Kon T, Saiki M, Matsumoto $Y$, Uchino Y, Yokoi N, Kinoshita S, Tsubota K: The features of dry eye disease in a Japanese elderly population. Optom Vis Sci 2006, 83(11):797-802.

17. Schaumberg DA, Dana R, Buring JE, Sullivan DA: Prevalence of dry eye disease among US men: estimates from the Physicians' Health Studies. Arch Ophthalmol 2009, 127(6):763-768.

18. DEWS: The definition and classification of dry eye disease: report of the definition and classification subcommittee of the international dry eye workshop (DEWS). Ocul Surf 2007, 5(2):75-92.

19. Han SB, Hyon JY, Woo SJ, Lee JJ, Kim TH, Kim KW: Prevalence of dry eye disease in an elderly Korean population. Arch Ophthalmol 2011, 129(5):633-638.

20. Goujon-Bellec S, Demoury C, Guyot-Goubin A, Hemon D, Clavel J: Detection of clusters of a rare disease over a large territory: performance of cluster detection methods. Int J Health Geogr 2011, 10:53.

21. Lemke D, Mattauch V, Heidinger O, Pebesma E, Hense HW: Detecting cancer clusters in a regional population with local cluster tests and Bayesian smoothing methods: a simulation study. Int J Health Geogr 2013, 12(1):54

22. Salinas-Perez JA, Garcia-Alonso CR, Molina-Parrilla C, Jorda-Sampietro E, Salvador-Carulla L: Identification and location of hot and cold spots of treated prevalence of depression in Catalonia (Spain). Int J Health Geogr 2012, 11:36.

23. Lee JT, Shin D, Chung Y: Air pollution and daily mortality in Seoul and Ulsan, Korea. Environ Health Perspect 1999, 107(2):149-154.

24. Wang TJ, Wang IJ, Hu CC, Lin HC: Comorbidities of dry eye disease: a nationwide population-based study. Acta Ophthalmol 2012, 90(7):663-668.

25. Chun YH, Kim HR, Han K, Park YG, Song HJ, Na KS: Total cholesterol and lipoprotein composition are associated with dry eye disease in Korean women. Lipids Health Dis 2013, 12:84

26. Uchino M, Nishiwaki Y, Michikawa T, Shirakawa K, Kuwahara E, Yamada M, Dogru M, Schaumberg DA, Kawakita T, Takebayashi T, Tsubota K: Prevalence and risk factors of dry eye disease in Japan: Koumi study. Ophthalmology 2011, 118(12):2361-2367.

27. Sahai A, Malik P: Dry eye: prevalence and attributable risk factors in a hospital-based population. Indian J Ophthalmol 2005, 53(2):87-91.

28. Uchiyama E, Aronowicz JD, Butovich IA, McCulley JP: Increased evaporative rates in laboratory testing conditions simulating airplane cabin relative humidity: an important factor for dry eye syndrome. Eye Contact Lens 2007, 33(4):174-176.

29. Teson M, Gonzalez-Garcia MJ, Lopez-Miguel A, Enriquez-de-Salamanca A, Martin-Montanez V, Benito MJ, Mateo ME, Stern ME, Calonge M: Influence of a controlled environment simulating an in-flight airplane cabin on dry eye disease. Invest Ophthalmol Vis Sci 2013, 54(3):2093-2099.

30. Barabino S, Shen L, Chen L, Rashid S, Rolando M, Dana MR: The controlledenvironment chamber: a new mouse model of dry eye. Invest Ophthalmol Vis Sci 2005, 46(8):2766-2771.

31. Lopez-Miguel A, Teson M, Martin-Montanez V, Enriquez-de-Salamanca A, Stern ME, Calonge M, Gonzalez-Garcia MJ: Dry eye exacerbation in patients exposed to desiccating stress under controlled environmental conditions. Am J Ophthalmol 2014, 157(4):788-798. e782.

32. Alex A, Edwards A, Hays JD, Kerkstra M, Shih A, de Paiva CS, Pflugfelder SC: Factors predicting the ocular surface response to desiccating environmental stress. Invest Ophthalmol Vis Sci 2013, 54(5):3325-3332.

33. Galor A, Kumar N, Feuer W, Lee DJ: Environmental factors affect the risk of dry eye syndrome in a United States veteran population. Ophthalmology 2014, 121(4):972-973. e971.

34. Behrens A, Doyle JJ, Stern L, Chuck RS, McDonnell PJ, Azar DT, Dua HS, Hom M, Karpecki PM, Laibson PR, Lemp MA, Meisler DM, Del Castillo JM, O'Brien TP, Pflugfelder SC, Rolando M, Schein OD, Seitz B, Tseng SC, van Setten G, Wilson SE, Yiu SC, Dysfunctional tear syndrome study group: Dysfunctional tear syndrome: a Delphi approach to treatment recommendations. Cornea 2006, 25(8):900-907.

35. Hyon JY, Kim HM, Lee D, Chung ES, Song JS, Choi CY, Lee J: Korean guidelines for the diagnosis and management of dry eye: development and validation of clinical efficacy. Korean J Ophthalmol 2014, 28(3):197-206.

36. Pult $H$, Purslow C, Murphy PJ: The relationship between clinical signs and dry eye symptoms. Eye (Lond) 2011, 25(4):502-510.

37. Afonso AA, Monroy D, Stern ME, Feuer WJ, Tseng SC, Pflugfelder SC: Correlation of tear fluorescein clearance and Schirmer test scores with ocular irritation symptoms. Ophthalmology 1999, 106(4):803-810. 
38. Bjerrum KB: Test and symptoms in keratoconjunctivitis sicca and their correlation. Acta Ophthalmol Scand 1996, 74(5):436-441.

39. Lemp MA: Advances in understanding and managing dry eye disease. Am J Ophthalmol 2008, 146(3):350-356.

40. Kweon S, Kim Y, Jang MJ, Kim Y, Kim K, Choi S, Chun C, Khang YH, Oh K: Data resource profile: the Korea National Health and Nutrition Examination Survey (KNHANES). Int J Epidemiol 2014, 43(1):69-77.

41. Kim Y: The Korea National Health and Nutrition Examination Survey (KNHANES): current status and challenges. Epidemiol Health 2014, 36:e2014002.

doi:10.1186/1476-072X-13-31

Cite this article as: Um et al.: Spatial epidemiology of dry eye disease: findings from South Korea. International Journal of Health Geographics 2014 13:31

\section{Submit your next manuscript to BioMed Central and take full advantage of:}

- Convenient online submission

- Thorough peer review

- No space constraints or color figure charges

- Immediate publication on acceptance

- Inclusion in PubMed, CAS, Scopus and Google Scholar

- Research which is freely available for redistribution 